\title{
تمرينات (Decol) وتأثيرها في تطوير القوه العضلية والمرونة الخاصة لمهاره الدحرجة
}

\section{الأمامية فتحاً للطالبات}

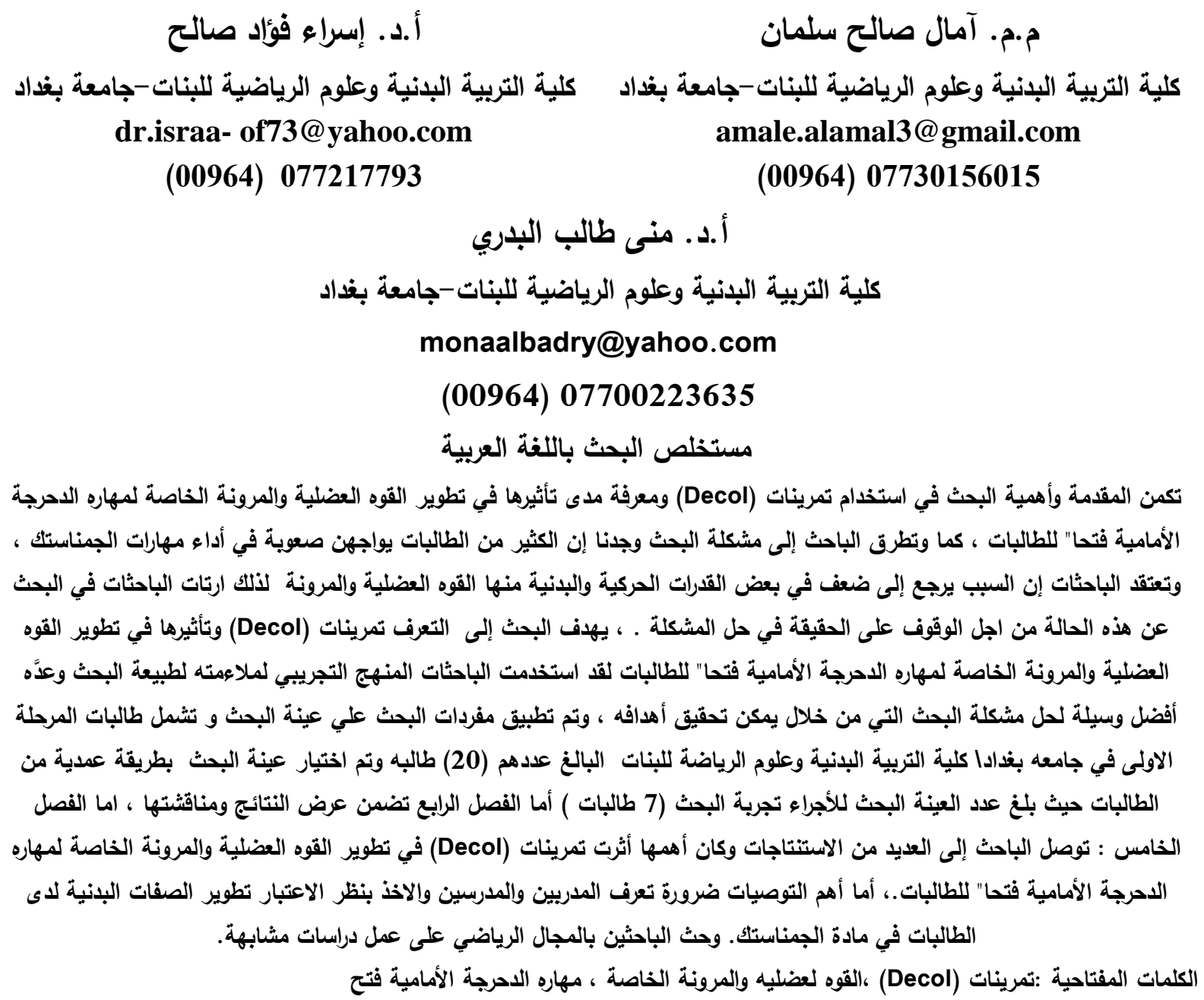

\section{ABSTRACT \\ Decol Exercises and Their Effect On the Development of Front Handspring Muscle Strength and Flexibility In Female Students \\ Asst. Inst. Amal Majed Prof. Dr. Israa Foad Prof. Dr. Muna Taleb College of Physical Education and Sport Sciences for Women}

The research aimed at identifying the effect decol exercises on muscular strength and flexibility of front handspring in female students. The problem of the research lies in female students facing difficulty in learning gymnastics' skill due to physical and motor abilities. The researchers used the experimental method on (20) female first Year College of physical education and sport sciences for women / university of Baghdad. The results showed the great effect of Decol exercises on developing muscle strength and flexibility in front handspring. Finally the researchers recommended developing physical abilities of female students in gymnastics as well as making similar studies.

Keywords: Decol exercises, muscle strength, flexibility, front handspring. 
يعدُ التدريب الرياضي من العلوم التي شهدت نطورًا واتساعًا سريعًا، الأمر الذي يستوجب من المدربين

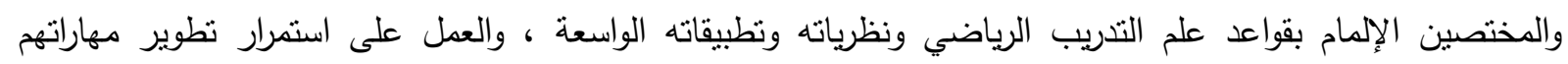

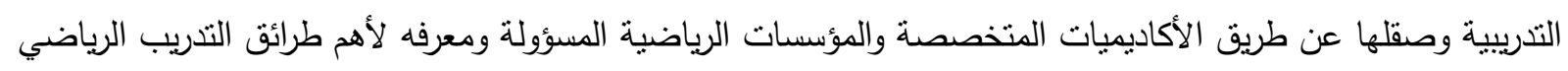

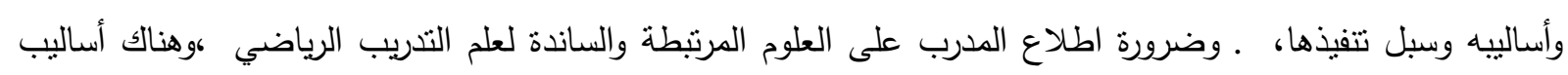

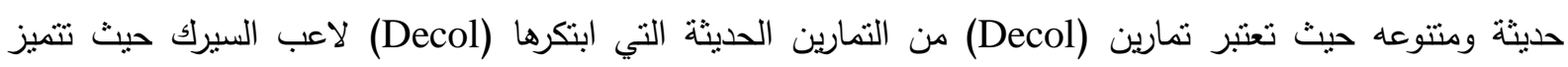

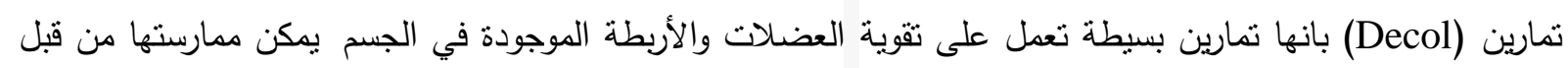

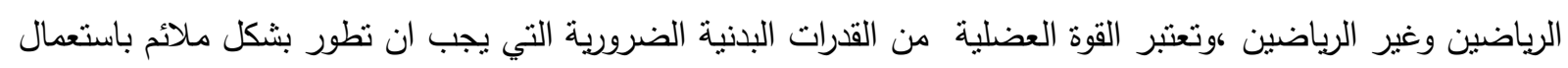
التمارين مختلفة التي تتم بطريقة مخططة ومدروسة ومنظمة، حيث تتلخص تلك الطريقة في إنشاء وتصميم برنامج ملائم للظروف الثخص، وتحديد طبيعة العمل العضلي الخاص بجسم معين دون غيره، بأكمله، و. وتعد التربية الرياضية مظهراً

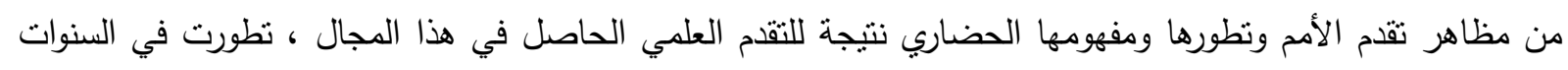
الأخيرة تطوراً ملحوظاً أدى إلى جعل الرياضة من مقومات الحياة اليومية والرياضية تميز المجتمعات باعتبارها ظاهرة

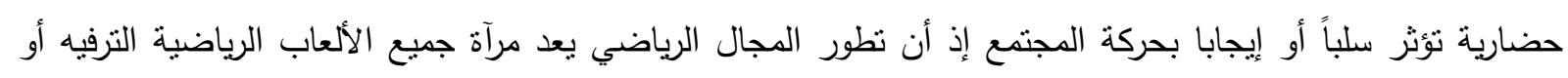

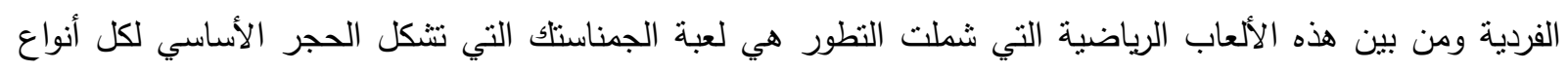

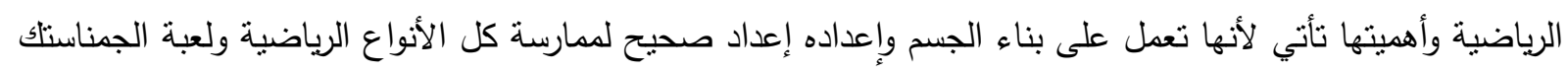

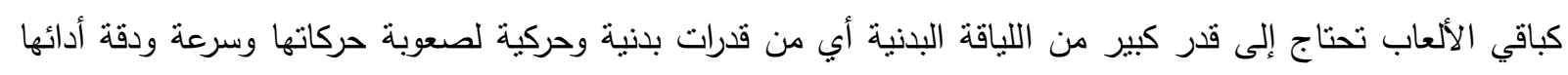

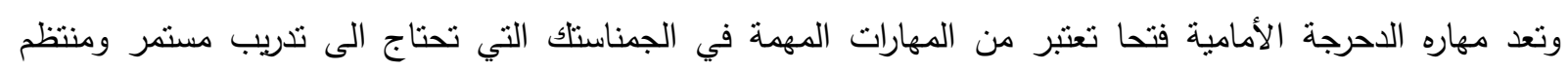

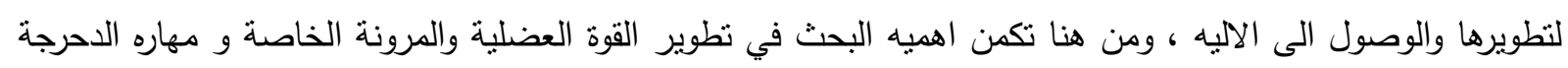

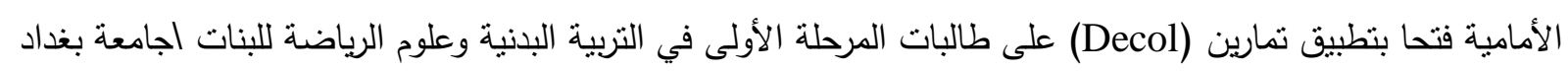

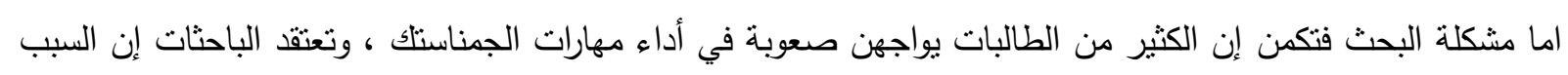

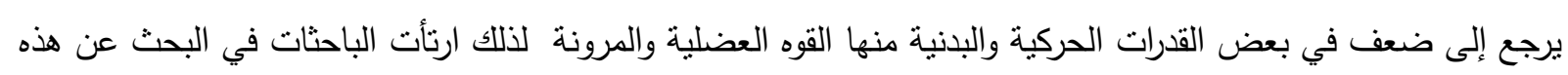
الحالة من اجل الوقوف على الحقيقة في حل المشكلة .اما اهداف البحث كانت التعرف على تأثثر استخدام تمرينات (Decol)

\section{الطريقة والأدوات:}

استخدمت الباحثات المنهج التجريبي بتصميم مجموعه التجريبية الواحدة لملائمته طبيعة البحث. وهو المنهج الذي يمكنه الاختبار الحقيقي لفروض الخاصة بالسبب او الأثر (حسانين، 1992، صفحة 122)

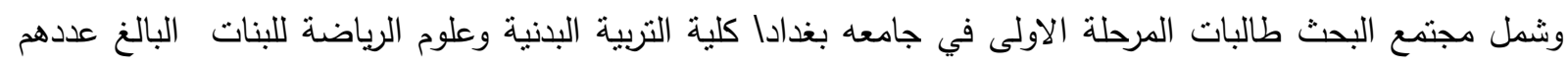

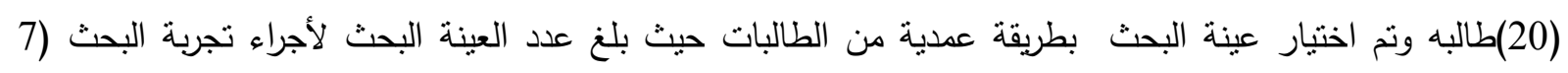
طالبات )، وبلغت نسبة العينة من المجتمع الأصل (40\%) ، وقد اختيرت البن عينة البحث وفقا لثروط الأتية: الاندفاع

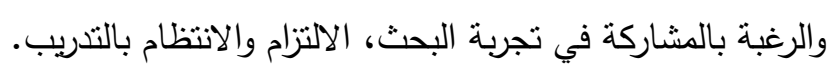

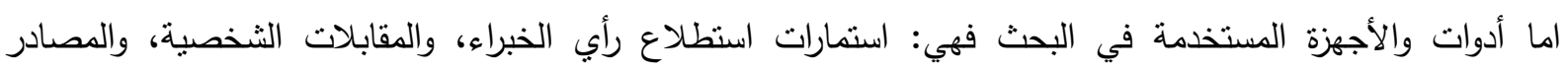
والمراجع العربية، واستمارات تسجيل البيانات، وشريط قياس، وحاسبة الكترونية، ساعة توقيت، جهاز الديناموميتر ، جهاز ريستامينز لقياس الطول والوزن، والمسطبة. 
اختبار القفز العمودي من الثبات: (الحكيم، 2004، صفحة 161) الهدف من الاختبار :قُّاس القوة لعضلات الاطراف السفلى.

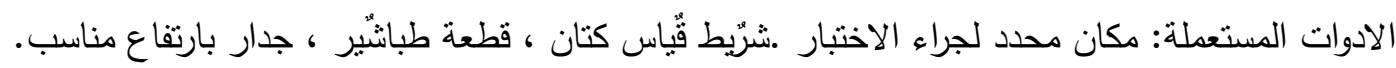

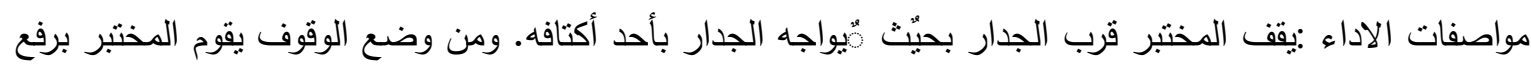

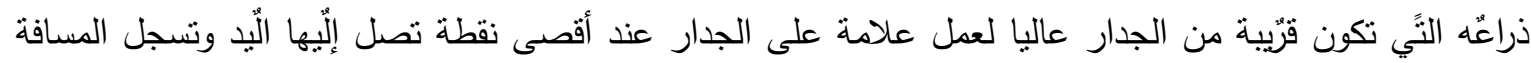

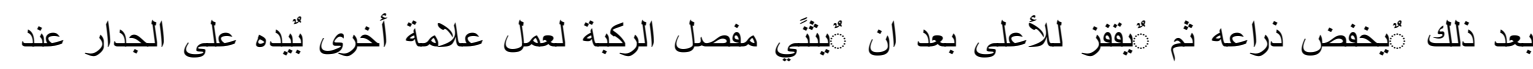

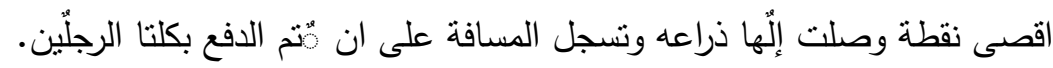
طريقة التسجيل:

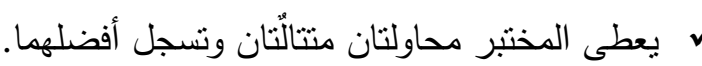
ل تقاس المسافة الواقعة بُن العلامة الاولى والعلامة الثانية بالسنتُيمتر والتَّي تعبر عن القوة لعضلات الاطراف السفلى.

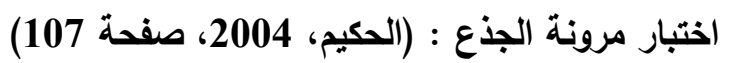

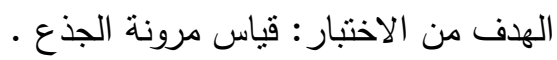

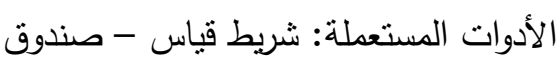
مواصفات الأداء : يجلس المختبر مواجها الصندوق بحيث يضغط بنطن القدمين على الوجه المقابل للصندوق

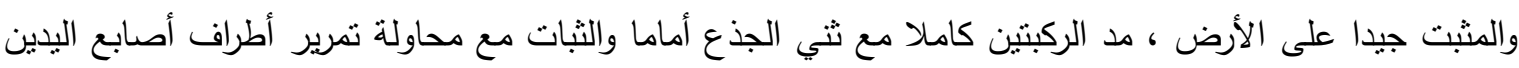

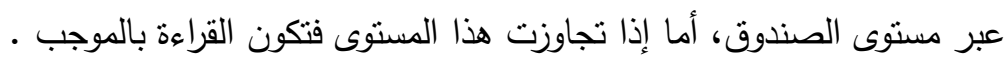

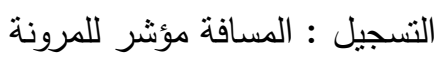
اختبار مهارة الاحرجة الأمامية فتحا على بساط الحركات الأرضية (الحكيم، 2004، صفحة 115).

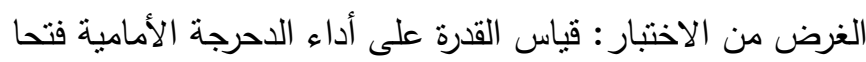

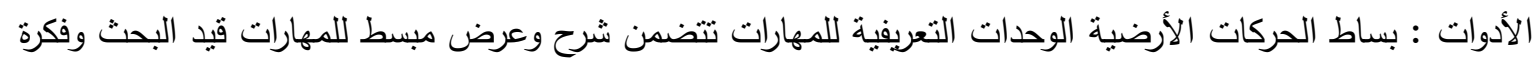
عامة عن كيفية أدائه الغرض التهيؤ للاختبارات القبلية أجراء الاختبار : يقوم المختبر بأداء الدحرجة الأمامية فتحا على بساط الحركات التهات الارضية.

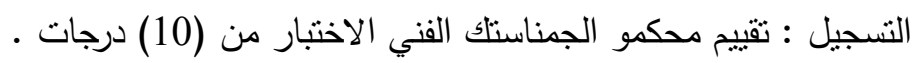
عدد المحاولات : تعطى محاولتان للمختبر وتأخذ أفضلوهما. التجارب الاستطلاعية: التجربة الاسنطلاعية هي " تجربة صغيرة يقوم بها الباحث لاختبار مدى صلاحية التجربة الرئيسية وتكمن أهميتها في الوقوف على السلبيات التي ستواجه الباحث لتفاديها في التجربة الرئيسية (محجوب، 1988، 1988، صفحة

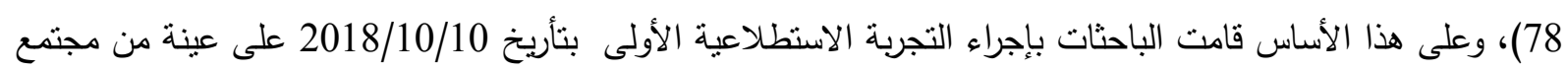
البحث وبعدد (4) طالبات من خارج عينة البحث الرئيسية ،و أعيدت التجربة الاستطلاعية بعد أسبوع بتأريخ

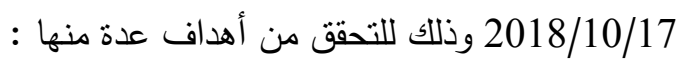
التعرف على الصعوبات التي يمكن إن تحدث خلال تطبيق التجربة الرئيسية لأجل وضع الحلول لها التأكد من صلاحية الأجهزة والأدوات التأكد من صلاحية وملائمة الاختبارات لإفراد العينة

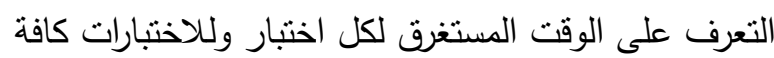

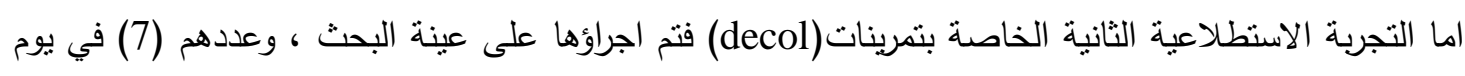
(الخميس)الموافق ( 119 110 2018 ) وكان الهدف منها: 
معرفة التكرارات الاقيقة لأداء كل تمرين.

التعرف على الزمن المستغرق لكل تمرين وزمن العمل.

اجراء بعض التعديلات للتدريبات الخاصة لزيادة دقة الهدف منها.

وتم إجراء الاختبارات القبلية لعينة البحث في يوم (الاثثن)الموافق (10/20) عند الساعة (العاشرة) في قاعة

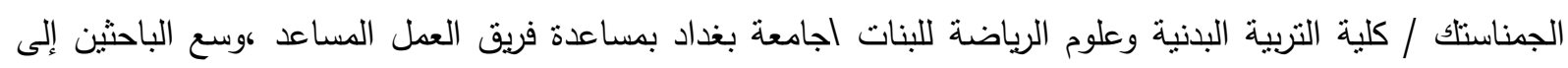

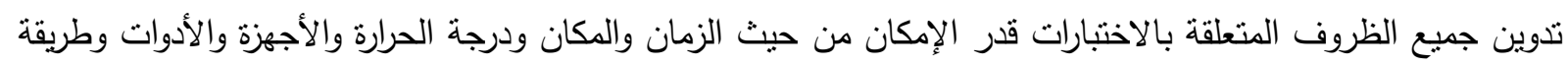
تتفيذ الاختبارات وذلك لمحاولة تهيئة الظروف نفسها أو ما يشابها عند إجراء الاختبارات البعدية.

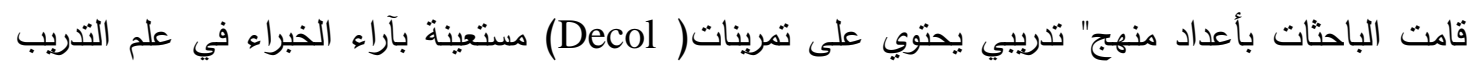

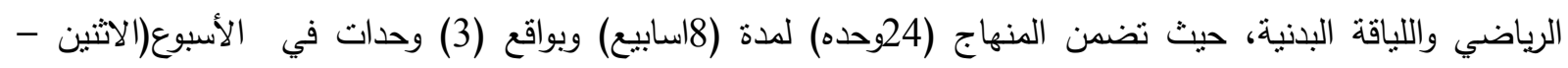

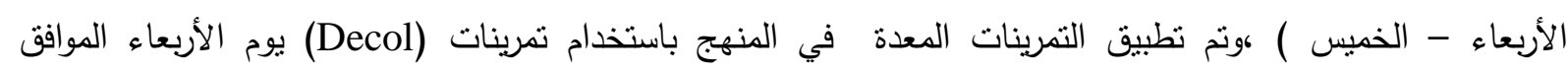

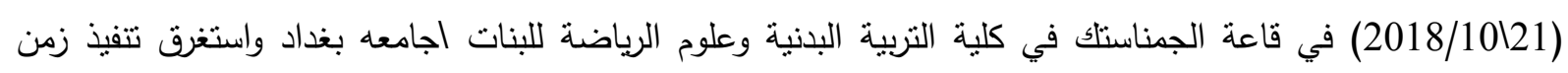
الوحدة التدريبية ( 30دقيقه ) ، وتم وضع مكونات الحمل التدريب حسب قدرات وعمر العينة وحسب منطلبات الاسلوب . تم اجراء الاختبارات البعدية حيث قامت الباحثات على تهيئة الظروف نفسها التي أجريت فيها الاختبارات القبلية والمشابهة قدر الامكان من الناحية الزمانية والمكانية والأدوات المستخدمة والفريق العمل المساعد نفسه في الاختبارات القبلية كافة، وبعد الانتهاء من تطبيق تمرينات (Decol) ميث تم اجراء الاختبارات البعدية في يوم الاثثين الموافق القان

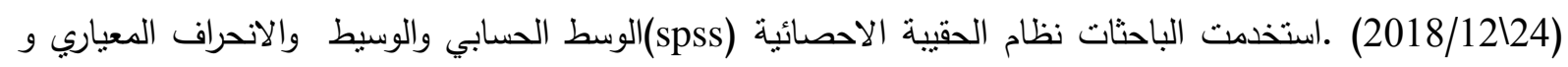
معامل الالتواء واختبار (T) للعينات المتتاظرة.

النتائجج: جدول (2) يبين الاوساط الحسابية والانحرافات المعيارية والفروق وانحرافاتها وقيمة (t)المحسوبة والجدولية للاختبارين القبلي

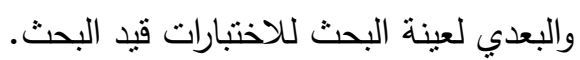

\begin{tabular}{|c|c|c|c|c|c|c|c|c|}
\hline \multirow[b]{2}{*}{ قالمحسوية } & \multirow[b]{2}{*}{ ف هـ } & \multirow[b]{2}{*}{ ف } & \multicolumn{2}{|c|}{ الاختبار البعدي } & \multicolumn{2}{|c|}{ الاختبار القبلي } & \multirow[b]{2}{*}{ وحدة } & \multirow[b]{2}{*}{ المتغيرات } \\
\hline & & & $\pm \varepsilon$ & سَن س & $\pm \varepsilon$ & سَن س & & \\
\hline 5.792 & $1 ، 81$ & 1.792 & 13.718 & 34.200 & 11.99 & 28.60 & نت & القوه العضلية للرجلين \\
\hline 6.36 & $4 \cdot 65$ & $08.4-$ & 3.64 & 13 & $83 ، 6$ & $0 ، 196$ & سم & المرونة \\
\hline 5,692 & 0,513 & 2,92 & 1,628 & 7,61 & 2,946 & 4,69 & درجة & الاحرجة الامامية فتحا \\
\hline
\end{tabular}

دال عند مستوى دلاله (0.5 ) ودرجه الحرية (6 ) والجدولية (1,943)

المناقشة:

وتعزو الباحثات هذا التطور إلى إن صفة القوه العضلية تعد مؤشرا مهما وعنصرا حيويا من عناصر اللياقة البدنية وقد تطورت بشكل ملحوظ وذلك بسبب التمارين التي تعتمد بشكل عام على أسلوب (decol).وإن طبيعة تدريبات القوة المتنثلة

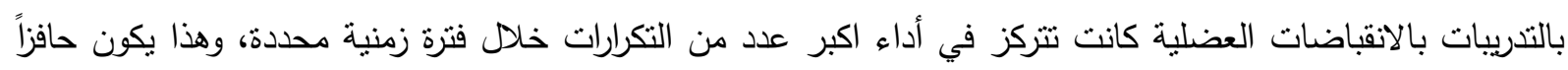

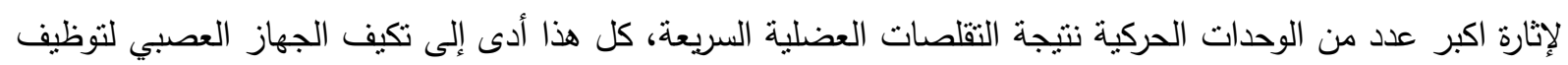

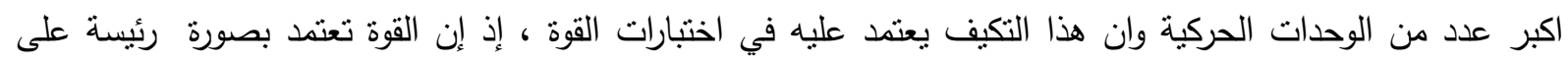

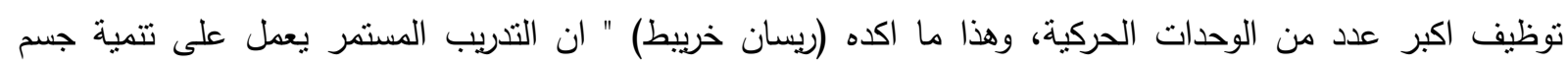


الرياضي كله وبصورة خاصة لتقوية مجموعة العضلات العاملة " (مجيد، 1997، صفحة 508) وهذا ما تتصف به تمارين (Decol) التمارين ثلاث مرات في الأسبوع تعتبر كافية لمعالجة معظم المشاكل وعند اداء التمارين يكون هناك تتويع في الثددد.

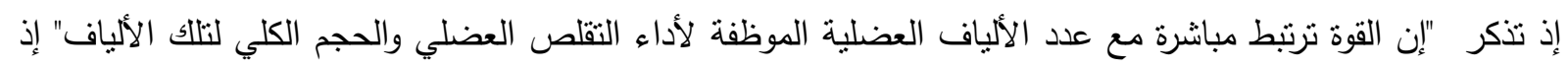
يذكر "أن أعلى شد في العضلة يمكن إنتاجه من خلال توظيف اكبر عدئ عدد من الوحدات الحركية وزيادة تعاقب الحافز

العصبي (محجوب، 1988، صفحة 2)

وإن البرنامج التدريبي شمل صفتنين بدنيتين في جميع الوحدات التدريبية، وذلك بالاعتماد على النتائج التي أظهرت في التي

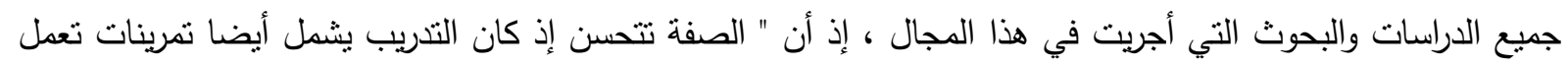
على تتمية الصفات البدنية الأخرى كالقوة والتحمل في نفس الوقت ، والعكس فات فان العان العمل والتركيز على تتمية صفة بدنية

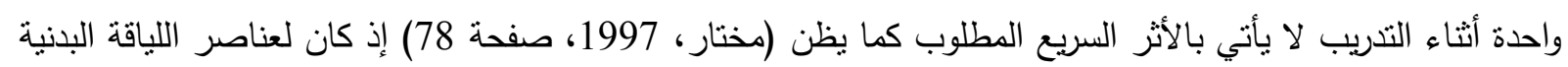

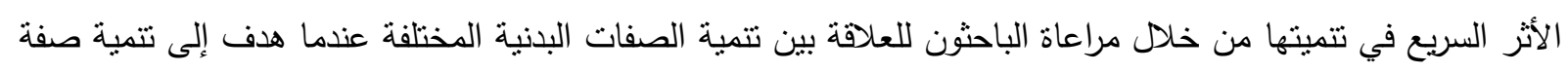
بدنية معينة إن " عند تتمية صفة بدنية فان الحمل المستخدم بهدف تتمية هذه الصفة يمكن أن يسهم إلى حد ما في تتمية

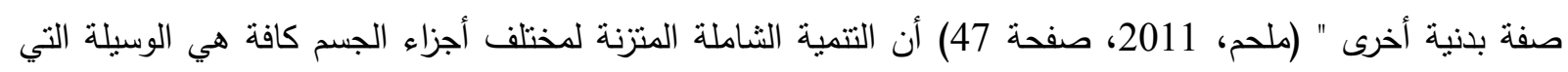
تمكن الفرد من أداء العمل الثاق مع بذل اقل جهد وطاقة ممكنة " (ثحاته، 1992، صفحة 23) أما فيما يخص المرونة

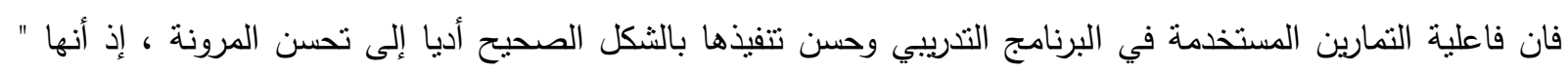

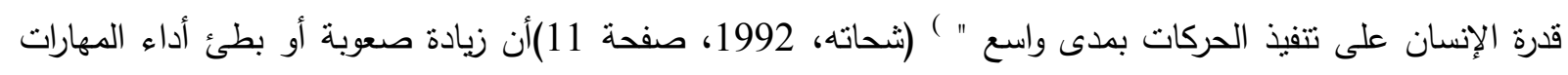

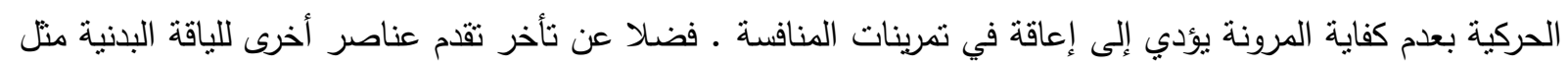

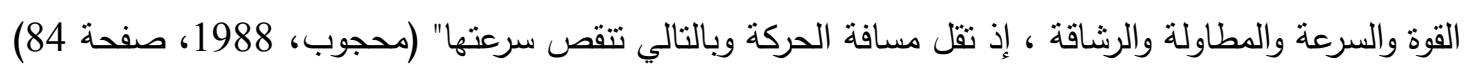

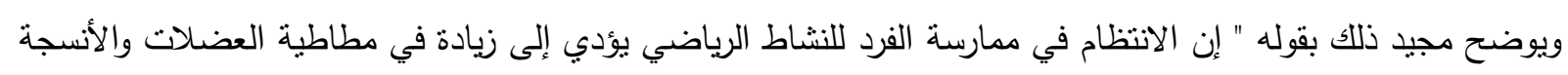

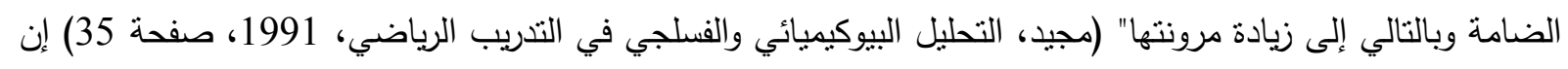

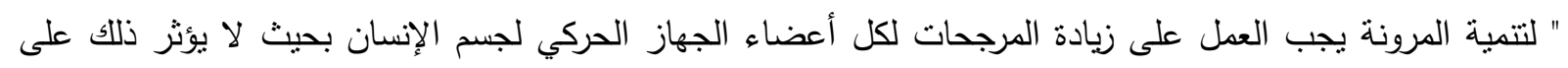

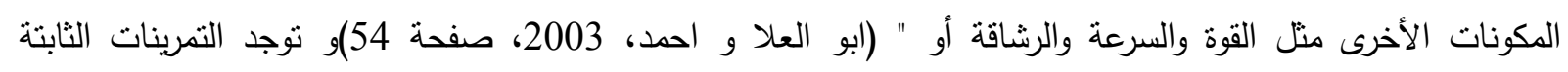

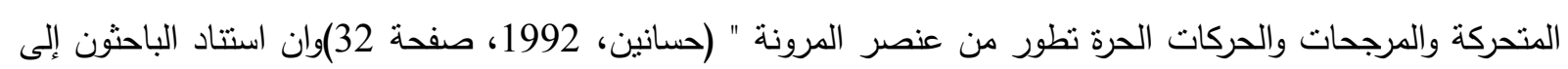

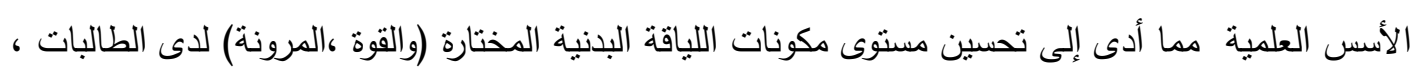

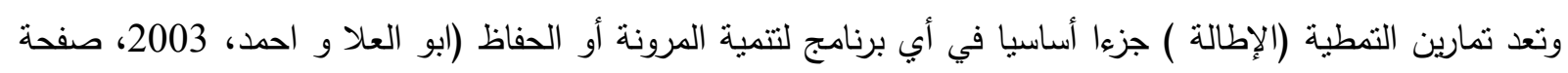

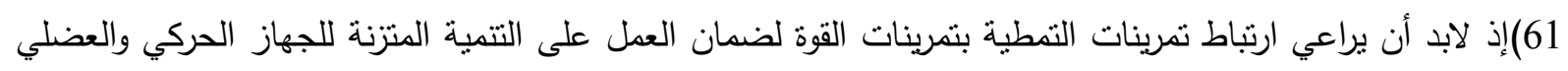

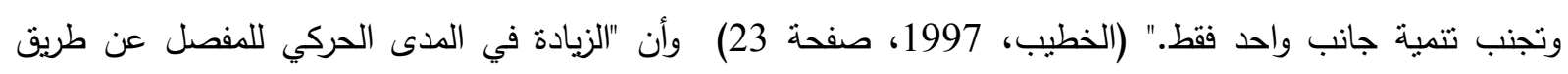

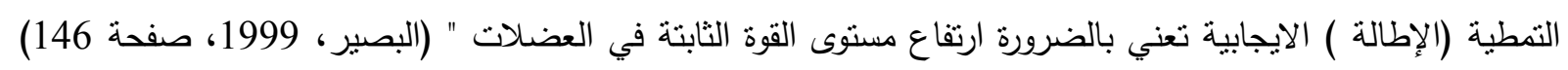

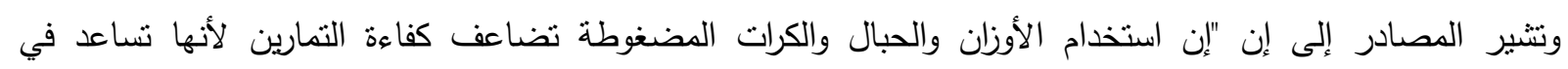

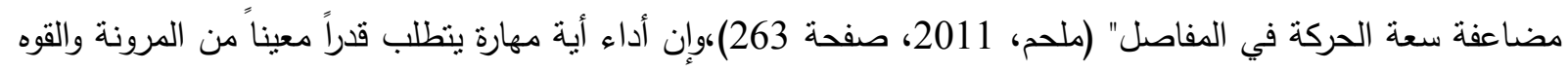

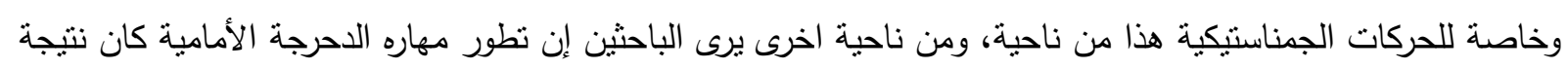

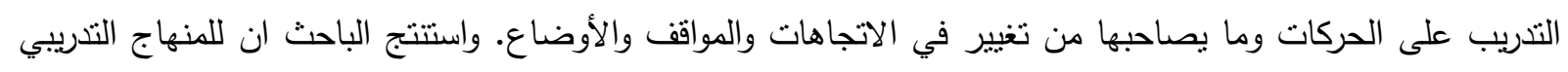

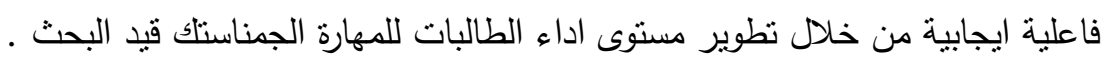


واوصى الباحثات بضرورة تعرف المدربين والمدرسين والاخذ بنظر الاعتبار تطوير الصفات البدنية لاى الطالبات في مادة الجمناستك وحث الباحثين بالمجال الرياضي على عمل دراسات مشابهة.

\section{المصادر}

ابو العلا احمد عبد الفتاح واحمد نصر اله. (2003). فسيولوجيا الرياضة البدنية ـ القاهرة : دار الفكر العربي . احمد عبد الفتاح ابو العلا ، و نصر الهه احمد. (2003). فسيولوجيا الرياضة البدنية ـ القاهرة : دار الفكر العربي .

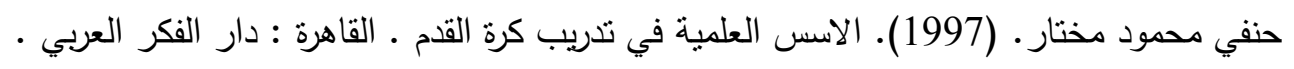

هيسان خريبط مجيد. (1991). التحليل البيوكيميائي والفسلجي في التدريب الرياضي. جامعة البصرة: دار الكحمة. ريسان خريبط مجيد. (1991). تطبيقات في علم الفسيولوجيا والتدريب الرياضي · جامعة البصرة : مطبعة دار

ريسان خريبط مجيد. (1997). تطبيقات في علم الفسيولوجيا والتدريب الرياضي . عمان : دار الثروق .

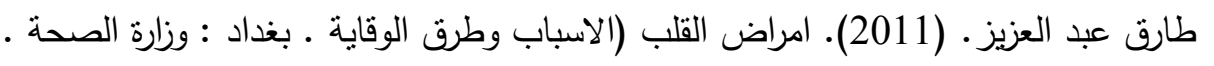

عائد عبد البصير • (1999). التدريب الرياضي والتكامل بين النظرية والتطبيق ـ القاهرة : دار الفكر العربي . عائد فاضل ملحم. (2011). الطب الرياضي الفسيولوجي قضايا ومشكلات معاصرة ـ الاردن : دار البازوري اربد . علي سلوم جواد الحكيم. (2004). الاختبار والقياس والاحصاء في المجال الرياضي ـ ـوزارة التعليم العالي والبحث العلمي : جامعة القادسية . محمد ابراهيم شحاته. (1992). دليل الجمباز الحديث ـ الاسكندرية : دار المعارف . محمد صبحي حسانين. (1992). قباس والتقويم في التربية الرياضية ـ ـدار الفكر العربي .

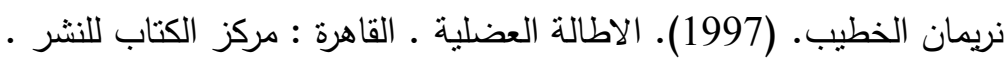
وجيه محجوب. (1988). طرق البحث العلمي ومناهجه ـ بغداد : مديرية دار الكتب . 